\title{
Akut Yetmezlikte Karaciğer Nakli; Tek Merkez Deneyimi
}

Gökhan ERTUĞRUL $^{1}$, Tumay YANARAL $^{2}$

\begin{abstract}
Öz
Akut karaciğer yetmezliği, ilerleyici karaciğer disfonksiyonudur. Karaciğer nakli, etkin bir tedavi seçeneğidir. Bu çalışmanın amacı akut karaciğer yetmezliği nedeniyle yapılan canlı vericili karaciğer nakillerini değerlendirmektir. Nisan 2014 ile Nisan 2019 tarihleri arasında, Medipol Üniversitesi Tıp Fakültesi Hastanesi Organ Nakli Bölümü’nde akut karaciğer yetmezliği nedeniyle canlı vericili karaciğer nakli yapılan 13 hasta retrospektif olarak değerlendirildi. Hastaların yaş ortalaması $21,1 \pm 20,9$ yıldı. Hastaların dokuzu $(\% 69,2)$ kadın ve yedisi $(\% 53,8)$ çocukluk $(<18$ yıl $)$ yaş grubunda idi. En sık toksik hepatit nedeniyle $(\% 38,5)$ karaciğer nakli yapıldı. Hastaların ortalama takip süresi $35,1 \pm 12,2$ aydı. Hastaların beşinde $(\% 38,5)$ komplikasyon gelişti. Hastalardan dördünde $(\% 30,7)$ mortalite görüldü. Genel sağkalım oranı 1 ve 5 yıllık sirasıyla \% 84,7 ve \% 69,3 idi. Akut yetmezlikte yapılan canlı vericili karaciğer nakillerinin başarılı olduğu görünmektedir.
\end{abstract}

Anahtar kelimeler: Akut karaciğer yetmezliği, karaciğer nakli, analiz
Yayın Bilgisi

Gönderi Tarihi: 12.05.2018

Kabul Tarihi: 29.08.2019

Online Yayın Tarihi: 31.12.2019

DOI: $10.26453 /$ otjhs.563470

Sorumlu Yazar

Gökhan ERTUGRUL.

Medipol Üniversitesi Tıp Fakültesi

Hepatobilier Cerrahi ve Organ Nakli

Merkezi.

TEM Avrupa Otoyolu Göztepe Çıkışı No: 1

34214,Bagcilar,Istanbul, Turkey. Phone:+902124607777

E-mail: mdgertugrul@gmail.com

\section{Liver Transplantations in Acute Failure; A Single Center Experiences}

Gokhan ERTUĞRUL $^{1}$, Tumay YANARAL ${ }^{2}$

\begin{abstract}
Acute hepatic failure is progressive liver dysfunction. Liver transplantation is an effective treatment option. The aim of this study was to evaluate the living donor liver transplantation due to acute liver failure. Between April 2014 and April 2019 at Medipol University Medical Faculty Hospital Organ Transplantation Department, 13 patients with living donor liver transplantations in acute failure was studied retrospectively. The mean age of the patients was $21.1 \pm 20,9$ years. Of these patients, nine $(69.2 \%)$ were female and seven $(53.8 \%)$ were children $(<18$ years old $)$. Liver transplantation was the most common cause of toxic hepatitis $(38.5 \%)$. The mean follow-up of the period was $35.1 \pm 12.2$ months. Complications were seen in five patients (38.5\%). Mortality was observed in four patients (30.7\%). Overall survival rate was $84.7 \%$ and $69,3 \%$ in 1 and 5 years, respectively. Living donor liver transplantation appears to be successful in acute failure.
\end{abstract}

Keywords: Acute liver failure, liver transplantation, analysis
Article Info

Received: 12.05 .2018

Accepted: 29.08 .2019

Online Published: 31.12 .2019

DOI: $10.26453 /$ otjhs. 563470

Corresponding Author

Gokhan ERTUGRUL.

Medipol Üniversitesi Tıp Fakültesi Hepatobilier Cerrahi ve Organ Nakli Merkezi.

TEM Avrupa Otoyolu Göztepe Çıkışı No: 1

34214,Bagcilar,Istanbul, Turkey. Phone:+902124607777

E-mail: mdgertugrul@gmail.com

1.Medipol Üniversitesi Tıp Fakültesi Hepatobilier Cerrahi ve Organ Nakli Merkezi İstanbul, Turkiye

2. Medipol Üniversitesi Tıp Fakültesi Anesteziyoloji ve Reanimasyon Bölümü İstanbul, Turkiye.

\section{GíRiș}

Son dönem karaciğer hastalığının en etkin tedavi şekli karaciğer naklidir. Akut nedenlerle yapılan karaciğer nakli acil bir durum olup ilk kez 1992 yılında yayınlanmıştır. ${ }^{1}$ Akut karaciğer yetmezliği karaciğer hastalığı olmayan bir kişide ilerleyici karaciğer disfonksiyonu, nörolojik disfonksiyon ve koagülopatiyi içerir. ${ }^{2}$ Akut karaciğer yetmezliği nadir görülen bir durum olup son derece mortal seyreder. Tedavi edilmeyen hastalarda mortalite oran1 \%70' i bulabilir. ${ }^{3}$ Akut karaciğer yetmezliğinin ana nedenleri, hepatotoksik ilaçlar (Parasetamol), virüs enfeksiyonları (Hepatit A,B ve E), metabolik nedenler (Wilson Hastalığı), vasküler nedenler (Budd Chiari Sendromu) ve mantar (Amanita Falloides) intoksikasyonudur. ${ }^{4-6}$ Bu çalışmanın amacı akut karaciğer yetmezliği nedeniyle yapılan canlı vericili karaciğer nakillerini değerlendirmektir.

MATERYAL VE METOD 


\section{Hastalar}

Nisan 2014 ile Nisan 2019 tarihleri arasında, Medipol Üniversitesi Tıp Fakültesi Hastanesi Organ Nakli Bölümü'nde akut karaciğer yetmezliği nedeniyle canlı vericili karaciğer nakli yapılan 13 hasta retrospektif olarak değerlendirildi. $\mathrm{Bu} 13$ hastanın demografik özellikleri, etiyolojik faktörleri, INR (International Normalized Ratio) ve amonyak değerleri, kullanılan greft tipi, soğuk ve sıcak iskemi süreleri ile komplikasyon ve mortalite oranları incelendi.

\section{Nakil Sonrası Takip}

Hastalara karaciğer nakli sonrası standart immunsüpresif tedavi olarak ömür boyu kullanılacak Kalsinörin İnhibitörleri (takrolimus veya siklosporin), ilk bir y1 kullanılacak Mikofenolat Mofetil, ilk altı ay kullanılacak Prednizolon başlandı.

Hastalar karaciğer nakli sonrası taburculuklarından itibaren ilk ay haftada bir, ikinci ay onbeş günde bir, sonraki aylarda ise ayda bir kontrole geldi.

\section{Ístatistiksel Analiz}

İstatistiksel analiz için SPSS 22.0 (Windows için SPSS, 2007,Chicago) kullanıldı. Normal dağılım gösteren sürekli değişkenler, ortalama \pm Standart sapma olarak verildi. Parametrik değişkenler için istatistiksel analiz Student's Ttesti ile yapıldı. Niteliksel değişkenler yüzde olarak verildi ve kategorik değişkenler arasındaki korelasyon ki-kare testi ve Fisher's exact testi ile araştırıldı. İstatistiksel anlamlılık düzeyi $\mathrm{P}<0,05$ olarak tanımlandı.

\section{BULGULAR}

Hastaların yaş ortalaması $21,1 \pm 20,9$ yıldı. Hastaların dokuzu $(\% 69,2)$ kadın, dördü $(\% 30,8)$ erkek ve yedisi $(\% 53,8)$ çocuk $(<18$ yaş) , altısı $(\% 46,2)$ erişkindi. Hastaların ortalama vücut kitle indeksi 20,3 $\pm 5,5$ kilogram/ metrekare $\left(\mathrm{kg} / \mathrm{m}^{2}\right)$ idi. Model for End-Stage Liver Disease (MELD) skoru ortalamas1 23 (16-32), Pediatric End-Stage Liver Disease (PELD) skor ortalamas1 16 (-6$37)$ idi. Hastaların yedisi $(\% 53,6)$ evre 3 , altıs1 $(\% 46,4)$ evre 2 hepatik ensefalopatide idi ve tüm hastalar nakile kadar olan bekleme sürecinde yoğun bakımda takip edildi (Tablo1).

Hastaların laboratuvar tetkiklerinden ortalama International Normalized Ratio (INR) 5,6 $\pm 2,4$, ortalama amonyak 160,6 $\pm 61,3$ mikromol/Litre $(\mu \mathrm{mol} / \mathrm{L})$ idi

Etiyolojide beş $(\% 38,5)$ hastaya toksik hepatit (Parasetamol) nedeniyle, dört $(\% 30,8)$ hastaya herhangi bir neden saptanmayıp, iki $(\% 15,4)$ hastaya mantar intoksikasyonu nedeniyle ve iki $(\%$ 15,4) hastaya Wilson Hastalığı nedeniyle canlı vericili karaciğer nakli yapıld1. 
Greft olarak altı $(\% 46,2)$ hastaya karaciğer sol lob lateral segment, beş $(\% 38,4)$ hastaya karaciğer sağ lob ve iki $(\% 15,4)$ hastaya karaciğer sol lob kullanıldı.

Ortalama soğuk iskemi süresi $83,8 \pm 48,5$ dakika, sicak iskemi süresi ise $39,5 \pm 13,2$ dakika idi. Hastaların nakil sonrası ortalama hastanede kalış süresi 15,2士4,1 gündü.

Hastaların ortalama takip süresi $35,1 \pm 12,2$ aydı. Hastaların beşinde $(\% 38,5)$ komplikasyon gelişti. Safra kaçağı $(\% 7,7)$ ve safra yolu anastomoz darlığ $1(\% 30,7)$ görülen komplikasyonlardı. Hastalardan dördünde $(\% 30,7)$ mortalite görüldü. Tüm hastalarda mortalite nedeni bilier sepsis idi. Genel sağkalım oranı 1 ve 5 yıllık sırasıyla $\% 84,7$ ve $\% 69,3$ idi.

\section{TARTIŞMA}

Son dönem karaciğer hastalığının en etkin tedavi şekli karaciğer naklidir. Akut nedenlerle son dönem karaciğer hastalığı gelişen hastalarda karaciğer nakli aciliyeti olan bir durum haline gelmektedir. Dünya genelinde tüm karaciğer nakillerinin yaklaşık \%10'u akut nedenlerle yapılmaktadır., ${ }^{3,6}$ Kadavradan karaciğer naklinin donör organ azlığ nedeniyle sınırlı olduğu ülkelerde canlı vericili karaciğer nakli ön plana çıkmaktadır. Akut nedenlerle karaciğer nakli yapılması gereken hastalarda, canlı donör hazırlığı sırasında geçen zaman beraberinde mortalite artışını getirebilmektedir. $^{7,8}$ Çalışmamızda, akut karaciğer yetmezliği nedeniyle yapılan canlı vericili karaciğer nakillerinin sonuçlarını değerlendirmeyi ve literatür verileri ile karşılaştırmayı amaçladık.

Akut karaciğer yetmezliği karaciğer hastalığ olmayan kişide ilk klinik semptomdan sonraki 8 hafta içerisinde sarılık, koagülopati ve hepatik ensefalopati gelişmesiyle karakterizedir. ${ }^{6,7}$ Akut karaciğer yetmezliği nadir görülen bir durum olup son derece mortal seyreder. ${ }^{2} \mathrm{Bu}$ nedenle akut karaciğer yetmezliği son derece acil bir durumdur. Özellikle International Normalized Ratio (INR) ve amonyak seviyesi önemli prognostik faktörler olup yüksek olması kötü prognozu göstermektedir. ${ }^{8,9}$ Çalışmamızda hastaların ortalama International Normalized Ratio (INR) $5,6 \pm 2,4, \quad$ ortalama amonyak $160,6 \pm 61,3$ mikromol/Litre $(\mu \mathrm{mol} / \mathrm{L})$ idi. $\mathrm{Bu}$ değerler yüksek olup literatür ile uyumludur.

Akut karaciğer yetmezliğinde hepatik ensefalopatiyi değerlendirmek için West Haven kriterleri kullanılmaktadır. ${ }^{10,11}$ Buna göre evre 0 normal, evre 1 hafif farkında olma eksikliği, evre 2 laterjik, evre 3 somnolens ve evre 4 komadır. Çalışmamızda hastaların 7'si $(\% 53,6)$ evre 3,6 's1 $(\% 46,4)$ evre 2 hepatik ensefalopatide idi.

Akut karaciğer yetmezliği nedenleri arasında viral nedenler (Hepatit A, B, D ve E virusleri, 
Ebstein Barr virus, Sitomegalovirus, Varisello zoster virus enfeksiyonları), ilaçlar ve toksinler (mantarlardan özellikle Amanita Phalloides), (ilaçlardan özellikle Parasetamol, Halotan, Antitüberküloz ilaçlar, Sülfonamidler, Amoksisilin kavulonat, Makrolidler, Tetrasiklinler, Valproik asit, Disülfiram, Kokain), vasküler nedenler (Budd Chiari Sendromu, Veno-oklüzif hastalık), metabolik nedenler (Wilson hastalığgi) ve diğer nedenler (Otoimmun Hepatit, Bilinmeyen nedenler) say1labilir. ${ }^{12,13}$

Hastalarda kötü prognoz en s1k Wilson hastalığı, ilaçlar (parasetamol) ve mantar intoksikasyonuna bağlı akut yetmezlik durumlarında görülür. Wilson hastalığ otozomal resesif geçer ve bakır transport geninde defekle ilişkilidir. Bakır karaciğer, kornea ve beyin gibi dokularda birikerek oksidatif hasar oluşturur. Amanita falloides türü mantar intoksikasyonunda ise karaciğer böbrek ve diğer organlardaki hasar amatoksine bağlıdır. ${ }^{13,14}$

Çalışmamızda $5(\% 38,5)$ hastaya ilaca bağlı toksik hepatit (Parasetamol) nedeniyle, 4 $(\% 30,8)$ hastaya herhangi bir neden saptanmayip, $2(\% 15,4)$ hastaya mantar intoksikasyonu nedeniyle ve $2\left(\begin{array}{ll}\% & 15,4)\end{array}\right.$ hastaya Wilson Hastalığı nedeniyle canlı vericili karaciğer nakli yapıldı.

Akut karaciğer yetmezliğinin kendiliğinden gerileme oranı \%10-40 iken nakil bekleme sırasındaki ölüm oranı ise $\% 10 \quad-70$ arasındadır. $\mathrm{Bu}$ nedenle kadavra karaciğer naklinin az yapıldığ 1 ülkelerde canlı vericiden karaciğer nakli aciliyeti olan hastalar için öncelik kazanmaktadır. ${ }^{15-18}$ Merkezimizde toplam 13 hastaya akut karaciğer yetmezliği nedeniyle canlı vericiden karaciğer nakli yapılmıştır ve nakil bekleme sürecinde mortalite görülmemiştir.

Akut karaciğer yetmezliği nedeniyle karaciğer nakli yapılan hastalarda 5 yıllık genel sağkalım oranı \% 65-85 arasında bildirilmektedir. ${ }^{19-21}$ Çalışmamızda da 1 ve 5 yıllık genel sağkalım oranları sirasiyla $\% 84.7$ ve $\% 69.3$ olup literatür ile uyumludur.

Çalışmamızda bazı sınırlamalar mevcuttur. Bunlar çalışmanın retrospektif olması ve vaka sayısının az olmasidir.

Sonuç:Tartışma bölümünde belirtilen kısıtlamalara rağmen akut yetmezlikte yapılan canlı vericili karaciğer nakillerinin başarılı olduğu görünmektedir.

\section{KAYNAKLAR}

1. Matsunami H, Makuuchi M, Kawasaki S, et al. Living-related liver transplantation in fulminant hepatic failure. Lancet. 1992;340:1411-1412.

2. Lee WM, Stravitz RT, Larson AM. Introduction to the revised American Association for the Study of Liver Diseases 
Position Paper on acute liver failure 2011.Hepatology. 2012;55:965-967.

3. O'Grady JG. Liver transplantation for acute liver failure. Best. Pract. Res. Clin. Gastroenterol. 2012;26:27-33.

4. Bernal W, Wendon J. Acute liver failure. N. Engl. J. Med. 2013;369:2525-2534.

5. Krawczyk M, Grąt M, Barski K, et al. 1000 liver transplantations at the Department of General, Transplant and Liver Surgery, Medical University of Warsaw analysis of indications and results. Pol. Przegl. Chir. 2012;84:304-312.

6. Nyckowski P, Skwarek A, Zieniewicz K, et al. Orthotopic liver transplantation for fulminant hepatic failure. Transplant Proc. 2006;38:219-220.

7. Bhaduri B, Mieli VG. Fulminant hepatic failure: pediatric aspects.Semin Liv Dis.1996;16:349-355.

8. Siddiqui MS, Stravitz RT. Intensive care unit management of patients with liver failure. Clin Liver Dis. 2014;18:957-978.

9. Goldaracena N, Spetzler VN, Marquez M, et al. Live Donor Liver Transplantation: A Valid Alternative for Critically Patients Suffering

10. From Acute Liver Failure. American Journal of Transplantation. 2015;15:15911597.
11. Sharma P, Sharma BC. Management of overt hepatic encephalopathy. J Clin Exp Hepatol. 2015;5:82-87.

12. Patidar KR, Bajaj JS. Covert and overt hepatic encephalopathy: diagnosis and management. Clin Gastroenterol Hepatol. 2015;13:2048-2061.

13. Trocello JM, Broussolle E, Girardot-Tinant $\mathrm{N}$, et al . Wilson's disease, 100 years later. Rev Neurol. 2013;169:936-943.

14. Jo WS, Hossain MA, Park SC. Toxicological profiles of poisonous, edible, and

15. medicinal mushrooms.Mycobiology. 2014;42:215-220.

16. Ferreira R, Romãozinho JM, Amaro $\mathrm{P}$, Ferreira M, Sofia C. Assessment of emergency liver transplantation criteriain acute liver failure due to Amanita phalloides. Eur J Gastroenterol Hepatol. 2011;23:1226-1232.

17. Bernal W, Cross TJ, Auzinger G, et al. Outcome after wait-listing for emergency liver transplantation in acute liver failure: a single centre experience. J Hepatol. 2009;50:306-313.

18. Park SJ, Lim YS, Hwang S, et al. Emergency adult-to-adult living-donor liver transplantation for acute liver failure in a hepatitis B virus 
19. endemic area. Hepatology. 2010;51:903911.

20. Matsui Y, Sugawara Y, Yamashiki N, et al. Living donor liver transplantation for fulminant hepatic failure. Hepatol Res. 2008;38:987-996.

21. Ikegami T, Taketomi A, Soejima Y, et al. Living donor liver transplantation for acute liver failure: a 10-year experience in a single center. J Am Coll Surg. 2008;206:412-418.

22. Yamashiki N, Sugawara Y, Tamura S, et al. Outcomes after living donor liver transplantation for acute liver failure in Japan: results of a nationwide survey. Liver Transpl. 2012;9:1069-1077.

23. Germani G, Theocharidou E, Adam R, et al. Liver transplantation for acute liver failure in Europe: outcomes over 20 years from the ELTR database. J Hepatol. 2012;57:288-296.

24. Mehrotra S, Mehta N, Rao PS, Lalwani S, Mangla V, Nundy S. Live donor liver transplantation for acute liver failure: A single center experience. Indian $\mathbf{J}$ Gastroenterol. 2018;37:25-30. 
Tablo 1. Hastaların demografik ve klinik özellikleri.

\begin{tabular}{lc}
\hline \multicolumn{2}{c}{ Demografik Özellikleri } \\
\hline Yaş (Yıl) & $21,1 \pm 20,9$ \\
Cinsiyet (Erkek/Kadın) (n/\%) & $4(\% 30,8) / 9(\% 69,2)$ \\
Çocuk / Erişkin (n/\%) & $7(\% 53,8) / 6(\% 46,2)$ \\
Vücut Kitle İndeksi (kilogram/metrekare) & $20,3 \pm 5,5$ \\
PELD (Pediatric End-Stage Liver Disease) Skoru & $15,6(-6 / 37)$ \\
MELD (Model for End-Stage Liver Disease) Skoru & $23(16-32)$ \\
\hline
\end{tabular}

Etiyoloji Faktörler (n/\%)

\begin{tabular}{lc}
\hline Toksik Hepatit (Parasetamol) & $5(\% 38,5)$ \\
Neden Saptanamayan & $4(\% 30,8)$ \\
Mantar & $2(\% 15,4)$ \\
Wilson & $2(\% 15,4)$ \\
\hline
\end{tabular}

\begin{tabular}{lc}
\hline & Laboratuvar Tetkikleri \\
\hline INR (International Normalized Ratio) & $5,6 \pm 2,4$ \\
& \\
Amonyak mikromol/Litre $(\mu \mathrm{mol} / \mathrm{L})$ & $160,6 \pm 61,3$ \\
\hline & \\
\hline Sol Lob Lateral Segment Karaciğer & Greft Tipi (n/\%) \\
Sağ Lob Karaciğer & $6(\% 46,2)$ \\
Sol Lob Karaciğer & $5(\% 38,5)$ \\
Soğuk İskemi Süresi (Dakika) & $2(\% 15,4)$ \\
Sicak İskemi Süresi (Dakika) & $83,8 \pm 48,5$ \\
Takip Süresi (Ay) & $39,5 \pm 13,2$ \\
Komplikasyon (+/-) (n/\%) & $35,1 \pm 12,2$ \\
Mortalite (+/-) (n/\%) & $5(\% 38,5) / 8(\% 61,5)$ \\
\hline
\end{tabular}

